\title{
Article \\ Device for Suppression of Aerosol Transfer in Close Proximity Settings
}

\author{
Yicheng Bao ${ }^{1,2, *, \dagger}$, Loïc Anderegg ${ }^{1,2,+} \mathbb{D}$, Sean Burchesky ${ }^{1,2, \dagger}$ and John M. Doyle $\mathrm{e}^{1,2, \dagger}$ \\ 1 Department of Physics, Harvard University, Cambridge, MA 02138, USA; anderegg@g.harvard.edu (L.A.); \\ burchesky@g.harvard.edu (S.B.); jdoyle@g.harvard.edu (J.M.D.) \\ 2 Harvard-MIT Center for Ultracold Atoms, Cambridge, MA 02138, USA \\ * Correspondence: bao@g.harvard.edu \\ + These authors contributed equally to this work.
}

check for

updates

Citation: Bao, Y.; Anderegg, L.; Burchesky, S.; Doyle, J.M. Device for Suppression of Aerosol Transfer in Close Proximity Settings. COVID 2021, 1, 394-402. https://doi.org/ $10.3390 /$ covid 1010033

Academic Editor: Martin Kröger

Received: 21 July 2021

Accepted: 7 September 2021

Published: 15 September 2021

Publisher's Note: MDPI stays neutral with regard to jurisdictional claims in published maps and institutional affiliations.

Copyright: (c) 2021 by the authors. Licensee MDPI, Basel, Switzerland. This article is an open access article distributed under the terms and conditions of the Creative Commons Attribution (CC BY) license (https:/ / creativecommons.org/licenses/by/ $4.0 /)$.

\begin{abstract}
Here we present a device that suppresses transfer of aerosol between nearby seating areas through the use of optically transparent, sound transmitting barriers and HEPA fan filter unit (FFU). A potential application of this device is to lower the risk of respiratory disease transmission in face-to-face, maskless meetings between individuals in a university setting. We evaluate overall aerosol transmission between users of the device. This is done for two different physical settings: a large space, such as a library, and a small space, such as an enclosed study room. We find that the device can provide lower aerosol transmission compared to the typical transmission between two individuals wearing surgical face masks separated by six feet.
\end{abstract}

Keywords: aerosol transfer; air filtration; COVID-19 risk mitigation

\section{Introduction}

The SARS-CoV-2 virus can transmit in the form of small respirable particles with $<10 \mu \mathrm{m}$ aerodynamic size diameter [1-6]. Particles of these sizes can remain suspended in air for a long period of time, which poses both a short range and long range transmission risk [7-9]. In contrast, significantly larger particles settle more readily under gravity and can also be blocked by solid barriers. Talking is a particularly notable and important activity in a university setting where verbal communication during instruction, especially small group conversations with peers, is a key component of learning. Talking is of particular concern for transmission of respiratory diseases as the output of viral particles from an infected person can be an order of magnitude or more greater compared to only breathing [10]. The size spectrum of aerosols emitted during talking is in the 1-10 $\mu \mathrm{m}$ range [11].

In a university setting, close contact face-to-face meetings between two or more people is desired in many contexts, including group studying, teaching sessions and office hours. Some COVID-19 risk mitigation guidelines indicate that many of these activities must be either online or carried out with people wearing face masks and maintaining a $6 \mathrm{ft}$ $(1.8 \mathrm{~m})$ separation at all times, the so-called " 6 foot masked" criterion [12]. Anecdotal evidence from students suggests that COVID-19 restrictions greatly degrade their educational and personal development. These restrictions also have various negative psychological effects on university students according to recent studies $[13,14]$. The aim of the device described and studied here is to achieve at least the same level of aerosol suppression between individuals as the " 6 foot masked" criterion, while allowing clear visual and aural communication, without masks.

\section{Materials and Methods}

The construction of the device is described briefly here. Three pieces of $1 / 4$ inch $(6.35 \mathrm{~mm})$ thick laser-cut acrylic panels are mounted together by 120 degree brackets and metal fasteners to form the shield main body. The main body is bolted down to a round 
wood table with 90 degree plastic anchors. Large slotted holes are cut on the shield panels and covered by 2 mil $(0.05 \mathrm{~mm})$ thick PET film as sound ports. These sound ports allow natural voice transmission through the panel while keeping the barrier function of panels. The PET films are very strong and can resist moderate impacts as well as daily cleaning without tearing.

The shield panels function to directly block large particles and droplets when users sneeze or cough. Small aerosol particles with relatively long suspension times, in contrast, have the potential to follow air flow lines around panels and into the room, eventually reaching another user of the device. A commercially available HEPA FFU is installed on top of the shield to provide a net air flow from edge of table to the top center. Aerosols generated by a user are pulled up and into the HEPA FFU, efficiently filtered by the filter unit and then the filtered air is exhausted back to the room.

Choice of the HEPA FFU is important for an effective shield design. The unit must provide a high enough air flow rate to create a face velocity flow at the user position that dominates the local air movement. This is in order to effectively draw aerosols into the HEPA FFU. Additionally, the exhaust port of the unit must direct air away from the sitting area at low velocity. This ensures the exhaust flow does not create a low-pressure region where unfiltered air flow from a user can bypass the filtration unit. We observed this phenomenon both in CFD simulation and experimental tests during development. Finally, to enhance the user experience, the unit must be adequately quiet.

It is hard to find a commercially available unit that meets all criteria. In our test device, a Honeywell HPA300 air filter is chosen. The Honeywell unit, mounted on top of the shield, requires a 90 degree air deflector on the exhaust vent to redirect the air flow vertically. This HEPA FFU provides 300 CFM $\left(510 \mathrm{~m}^{3} / \mathrm{h}\right)$ of air flow on the "Turbo" setting and 220 CFM $\left(374 \mathrm{~m}^{3} / \mathrm{h}\right)$ of air flow on the "Allergen" setting. We measure at the location of a user's head a noise level of $58 \mathrm{dBA}$ for the "Allergen" setting and $63 \mathrm{dBA}$ for the "Turbo" setting. Acceptable sound level is subjective. Some test users found "Turbo" acceptable, while others greatly preferred "Allergen". All of the aerosol mitigation evaluations below are carried out with filters on the "Allergen" setting.

The device is designed with visual barriers ("flaps") on the outside perimeter of the table to encourage users to stay within the effective area. These flaps extend outside the table from each acrylic panel and are made from off-white color nylon (see Figure 1). The flaps are installed to block the user's view when users might lean back from the table, which might reduce the shield effectiveness due to lower face velocity away from the table. Additional "tangent flaps" are installed to redirect the breathing flow along the edge of the table back into HEPA filter inlet area. This also reduces the effective opening area, increasing the face velocity. There are also "roofs" made of clear acrylic on top of each section which further reduce the leakage of aerosol into the room.

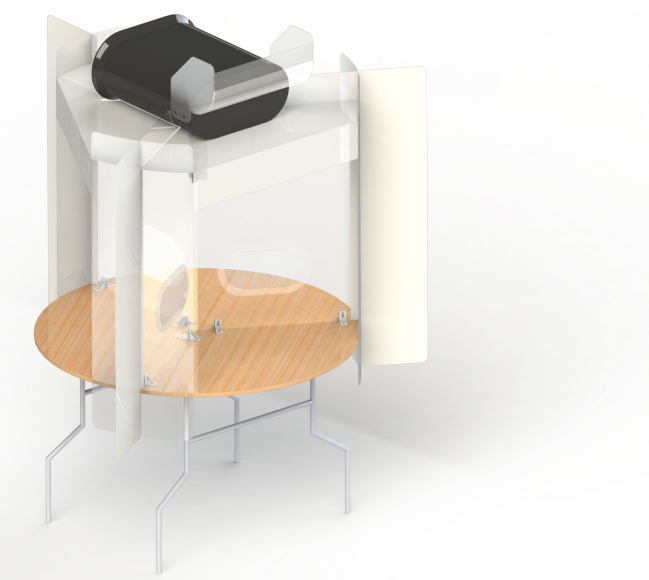

Figure 1. 3D rendering of the device. 
The reference device described here is designed for a three person setup, but it is possible to extend this to a larger group of people where larger table space and additional filtration units are available.

\section{Results}

\subsection{Aerosol Production, Measurement, and Calibrations}

The essential measurement approach is to generate small particles with an aerosol generator (AG) and determine at various locations the number density of small particles (aerosol number concentration) using a particle counter. We use a TSI 8026 AG to simulate aerosol emission from a user in a seating position at the table. A small duct with a fan attached is connected to the AG to eject the aerosol laden air with a flow rate of 5 CFM $\left(8.5 \mathrm{~m}^{3} / \mathrm{h}\right)$ at velocity $2 \mathrm{~m} / \mathrm{s}$, so as to approximate a person's air flow during talking [15]. TSI AeroTrak 9303 particle counters are used to measure the aerosol number concentration. The particle counter used in this paper has multiple channels for various particle size and only data from the " $0.3 \mu \mathrm{m}$ channel" is used in this paper to selectively investigate the particle size of interest. The " $0.3 \mu \mathrm{m}$ channel" of this particle counter counts particle size from $0.3 \mu \mathrm{m}$ up to $25 \mu \mathrm{m}$. There is also a " $5 \mu \mathrm{m}$ channel" which counts from $5 \mu \mathrm{m}$ to $25 \mu \mathrm{m}$. This " $5 \mu \mathrm{m}$ channel" reads $<0.1 \%$ of the reading from " $0.3 \mu \mathrm{m}$ channel" in all of our measurement results. This indicates that $>99.9 \%$ of the particles registered by the " $0.3 \mu \mathrm{m}$ channel" is within $0.3 \mu \mathrm{m}$ to $5 \mu \mathrm{m}$ range.

We aim to compare the device performance to the common COVID-19 risk mitigation guideline for face to face interactions, the " 6 foot masked" criterion. To do this, we experimentally measure particle number concentration on a circle with a radius of $6 \mathrm{ft}$ $(1.8 \mathrm{~m})$ with the AG in the center of the circle and then apply a mask correction factor. This is described in detail in Section 3.2.1. As our experimental measurements rely on stable production of aerosols, we calibrate the AG and find no more than $10 \%$ variation over a timescale of $20 \mathrm{~min}$, longer than the time to complete a set of measurements. This is described in Appendix A.

We measure the effectiveness of the device in two rooms with distinctly different local indoor environments: a "large space" and a "small space". The large space is characterized by high ceilings and a HVAC system that moves air with a low velocity and steady large scale circulation in the room. The dominant effect of air circulation in the large space is transport of aerosols away from a local source by the air currents and then exhausted or filtered, without filling the volume with a nearly uniform concentration of aerosols. We quantify aerosol concentrations around a $6 \mathrm{ft}(1.8 \mathrm{~m})$ radius from a local emission source, which provides the reference level to which we compare to the shield device (see Section 3.2).

The small space is a room with minimal HVAC air flow (e.g., typical building code value of 10 CFM $\left(17 \mathrm{~m}^{3} / \mathrm{h}\right)$ per person), low ceiling height and floor area such that the table and shields sit on the order of $6 \mathrm{ft}(1.8 \mathrm{~m})$ away from the walls on all sides. In this situation local air currents, lacking a defining global flow direction, spread the aerosols in the room without significant removal of suspended aerosols on a timescale relevant to the use of such rooms in a university setting. The result is that the room fills with aerosols, producing a nearly uniform full-room scale "background". The steady-state background level in the room is used as the comparison for the shield performance in this environment (see Section 3.3).

\subsection{Large Space}

The typical large space considered here, and where tests were performed, is a university library main reading room. Other examples of large indoor spaces include dining halls and public gathering areas typically with areas greater than $2000 \mathrm{sq} \mathrm{ft}\left(186 \mathrm{~m}^{2}\right)$ and ceiling heights greater than $12 \mathrm{ft}(3.7 \mathrm{~m})$. 


\subsection{1. "6 Foot Masked" Measurements}

We aim to compare the aerosol received by a user of the device to the amount that would, on average, be received by two people wearing face masks and maintaining a $6 \mathrm{ft}(1.8 \mathrm{~m})$ separation. The attenuation of aerosol between source and receiver due to mask wearing is given by a number designated as the "mask factor $=M$ ". Based on extensive literature, we use a value of $M=4.4$, which is an average of values from several sources [16-19]. The amount of aerosol exchanged between people with $6 \mathrm{ft}(1.8 \mathrm{~m})$ of separation is dependent on the air flow conditions. The case considered here is for large indoor spaces that have a large volume and typical airflows due to modern HVAC systems. The transmission of aerosol from one person to another depends on the specific direction of airflow and its relation to the position of the people. For example, if one person is directly downstream from the other person, then the transmission of aerosol is significantly higher. We seek to find the spatially averaged value, $A$, of the aerosol number concentration.

Measurements of aerosol number concentration are taken on a 16 point angular grid arranged in a circle of radius $6 \mathrm{ft}(1.8 \mathrm{~m})$ around the AG in the main room of an academic library Two levels in university library. In this test, the AG produces a constant supply of aerosols carried forward at $2 \mathrm{~m} / \mathrm{s}$. The measured values of aerosol number concentration are averaged over this grid to produce the " 6 foot masked" comparison value $C=A / M$. The 16 point grid is sampled twice over the course of approximately $15 \mathrm{~min}$, sufficiently long to allow the aerosols to travel with the room airflow. The data show a strong dependence of aerosol number concentration on the room air flow direction for this large indoor space. The background value is $3.9 \times 10^{3}$ particles $/ \mathrm{L}$, measured $20 \mathrm{ft}(6 \mathrm{~m})$ away from the AG. We measure an average concentration of $A=(7.2 \pm 0.3) \times 10^{3}$ particles $/ \mathrm{L}$ above background, around the $6 \mathrm{ft}(1.8 \mathrm{~m})$ radius circle. This value is an average of measurements made in two different locations that satisfy our "large space" criteria and should be representative of other large rooms with modern HVAC systems.

\subsubsection{Device Effectiveness}

We then test the device in the large room environment. The aerosol number concentration, $S$, is measured by two particle counters, each one in a separate user location (location 2 and 3 in Figure $2 b$ ), with the AG approximately positioned to simulate the mouth of a person seated at the table in the user location 1 . The background values are determined by measuring particle number concentration at a distance of $15-20 \mathrm{ft}(4.6-6 \mathrm{~m})$ from the device. The measured aerosol number concentration is found to be $S<4 \times 10^{2}$ particles/L above background in user location 2 and 3 . The aerosol number concentration in the user location 1 , where AG is placed, is about $6 \times 10^{5}$ particles/L above background. There is no significant difference between the measurement in two rooms. Although the latter value does not come into our determination of the performance of the device, it gives a sense of the very high suppression $(>1000)$ of particle number concentration between three user locations of the device. The measurements of the aerosol number concentration $(S)$ are used in combination with $C$ to define the improvement factor, $I=C / S=A /(S M)$, which is the figure of merit used to quantify the effectiveness of the device. The target of the device performance is $I>1$, indicating that the device outperforms the "6 foot masked" benchmark. From the measurements in the large space environment, we determine the improvement factor to be $I=4.1 \pm 0.2$. 

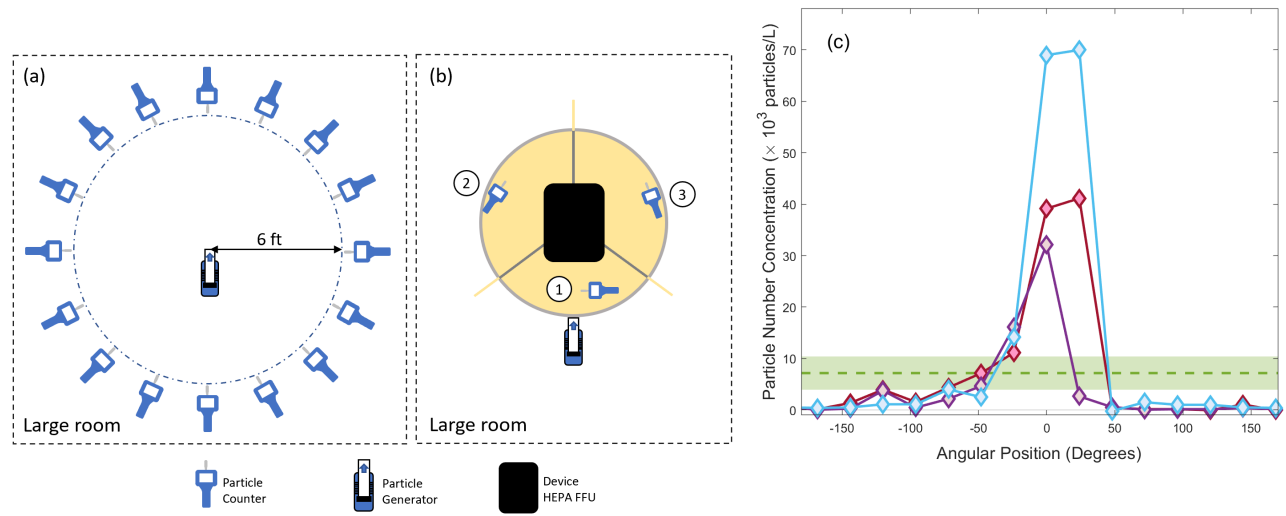

Figure 2. (a) Schematic of the large indoor space baseline measurement setup. aerosol number concentrations were measured at 16 equally spaced points on a circle of radius $6 \mathrm{ft}(1.8 \mathrm{~m})$ around the particle generator. (b) Schematic of the particle counter location for device effectiveness measurement setup. (c) Position dependent aerosol number concentration in the large space environment. The purple and red curves are independent measurements taken in room 1 . The blue curve was taken in room 2 . The green dotted line $\left(A=(7.2 \pm 0.3) \times 10^{3}\right.$ particles $\left./ \mathrm{L}\right)$ is the mean value averaged over the 16 point angular grid and averaged between the two rooms. The green shaded region indicates the 1-sigma error bar on the angular averaged value. The large peak seen in both rooms corresponds to the downwind direction of the room air flow provided by the building HVAC system. The room background $\left(3.9 \times 10^{3}\right.$ particles $\left./ \mathrm{L}\right)$ is measured $20 \mathrm{ft}(6 \mathrm{~m})$ away from the AG and subtracted.

\subsection{Small Space}

The typical small space considered here, and where tests were performed, is an enclosed group study room. Another common example of small spaces is offices, typically with areas of less than $500 \mathrm{sq} \mathrm{ft}\left(46 \mathrm{~m}^{2}\right)$ and ceiling heights above $10 \mathrm{ft}(3 \mathrm{~m})$ but less than $15 \mathrm{ft}(4.6 \mathrm{~m})$.

In the case of small spaces, the goal of achieving an improvement factor $I>1$ remains the same as with large spaces. A functional difference is that in the small space case, the room acts as an enclosed system. For comparison, in the large space, the effect of aerosol generation on the ambient particle number concentration is small. In particular, in the small space, the " 6 foot masked" situation is characterized by the particle number concentration throughout the room because the small room acts as an effective mixing box. With this distinction in mind, the essential procedure used for this measurement, and calculation of improvement factor, is the same as for the large space.

The small space has an area of $160 \mathrm{sq} f t\left(15 \mathrm{~m}^{2}\right)$ and is measured to have low $(<50 \mathrm{CFM}$ $\left.\left(85 \mathrm{~m}^{3} / \mathrm{h}\right)\right)$ fresh or highly filtered air ventilation. In order to mimic the condition given by a common COVID-19 mitigation guideline for the minimum flow rate per person of fresh air or highly filtered air (MERV 13 or better) provided by the HVAC system, we simulate as the baseline aerosol removal by turning on an auxiliary HEPA FFU (simply referred to as "room HEPA") with $300 \mathrm{CFM}\left(510 \mathrm{~m}^{3} / \mathrm{h}\right)$ flow rate placed at the corners of the room, approximately 2 feet from the wall. This is well above the typical modern building code requirements for indoor spaces(about $10 \mathrm{CFM}\left(17 \mathrm{~m}^{3} / \mathrm{h}\right)$ per person). Thus, our final determination of $A$ is conservative, as is our measured improvement factor, $I$. The device is placed at the center of the room with the AG output positioned at the edge of the table at the other user locations (see Figure 3). The particle counter sampling intake is placed at the edge of the table in the other two sectors. We measure the particle concentration versus time after the AG is turned on. The data collected is fitted to an exponential model $f(t)=$ $B \times e^{-\left(t-t_{0}\right) / \tau}+V$ which gives a determination of the equilibrium particle concentration $V$. The measured equilibrium aerosol number concentration in this baseline setup is $A_{e}=(4.82 \pm 0.04) \times 10^{4}$ particles $/ \mathrm{L}\left(A_{e}=V\right.$ extracted from the exponential model $)$. 

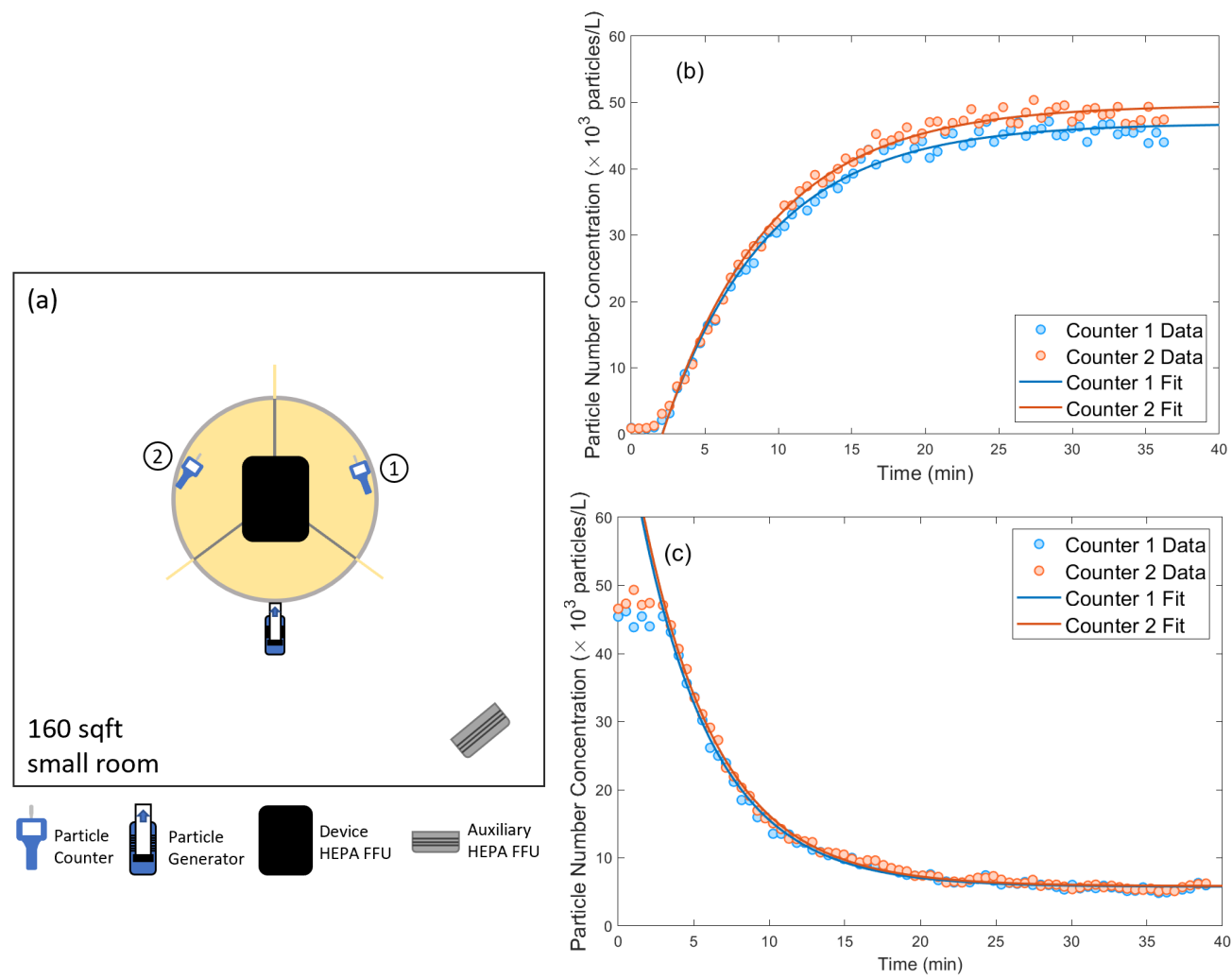

Figure 3. (a) Schematic of the small indoor space measurement setup. One auxiliary HEPA filter is placed in the corner of the room to simulate building HVAC. (b) Exponential model fit of the measured particle concentration with only the auxiliary HEPA filter running. This setup determines the baseline when the shield is not implemented. The estimated equilibrium is $(4.82 \pm 0.04) \times 10^{4}$ particles $/ \mathrm{L}$. (c) Exponential model fit of the measured particle concentration when turning on the HEPA filter on the device. The equilibrium particle concentration is around $(5.8 \pm 0.2) \times 10^{3}$ particles $/ \mathrm{L}$.

We then turn on the HEPA FFU (which is mounted to the top of the device). The data fitted by the exponential model shows an equilibrium aerosol number concentration of $S_{e}=(5.8 \pm 0.2) \times 10^{3}$ particles $/ \mathrm{L}$. The improvement factor is $I_{e}=C_{e} / S_{e}=A_{e} /\left(S_{e} M\right)=$ $1.89 \pm 0.07$. This also indicates that the device captures $88 \%$ of the aerosols generated by the users.

\subsection{Noise}

The noise sound level at user locations of the device is measured with the device HEPA filter running on the "Allergen" setting. The sound level meter is positioned at head height at the three locations. Sound level is the mean value measured using the A frequency-weighting. The result is summarized in Table 1.

Table 1. Noise sound level measurement at different user positions. The positions are labeled in Figure 3.

\begin{tabular}{cccc}
\hline Position: & $\mathbf{1}$ & $\mathbf{2}$ & $\mathbf{3}$ \\
\hline Allergen & $57 \mathrm{dBA}$ & $58 \mathrm{dBA}$ & $60 \mathrm{dBA}$ \\
Turbo & $63 \mathrm{dBA}$ & $63 \mathrm{dBA}$ & $62 \mathrm{dBA}$ \\
\hline
\end{tabular}

\section{Discussion}

For a small space with typical building HVAC system, it is clear that a simple passive shield (without HEPA FFU installed) is not enough to achieve aerosol transmission suppression comparable to " 6 foot masked" guideline. A passive shield can stop most large 
droplets but not aerosols. Once aerosol contaminated air mixed with room air, a HEPA FFU with much larger air flow is required to clean it up and keep equlibrium aerosol number concentration low. The device presented in this work solves this problem by adding an HEPA FFU close to the users which actively drags the air in and filters the aerosols before it mixes with room air.

For a large space, the HEPA FFU on the device can achieve enough face velocity to dominate the air flow over the room HVAC, suppressing the leakage of aerosol into room air. The air flow generated by the device HEPA FFU also lowers the sensitivity of orientation and arrangement of the devices in the room. A passive shield could be effective for suppressing one direction aerosol transmission if positioned correctly, but it would be less effective suppressing the transmission in the other direction and cannot prevent aerosol dispersing into clean room air.

\section{Conclusions}

In conclusion, we present a device design that allows for natural face to face interactions between multiple maskless users while effectively mitigating the risk of transfer of aerosols. The aerosol transmission attenuation of the device is evaluated in two environments, typical of a university setting. We compare measurements of aerosol transmission between users of the device to a reference setup simulating two individuals separated by $6 \mathrm{ft}$ and wearing surgical face masks. The result shows an improvement factor of $4.1 \pm 0.2$ for the "large space" and $1.89 \pm 0.07$ for the "small space". This provides a promising way of recovering some normal activities in a university setting while maintaining low risk of aerosol transmission of SARS-CoV-2 and other respiratory diseases.

Author Contributions: All authors listed were involved with all aspects of this manuscript. All authors have read and agreed to the published version of the manuscript.

Funding: This research was partially funded by Heising Simons Foundation.

Data Availability Statement: Not Applicable.

Acknowledgments: We thank Christopher Stubbs and Michael Springer for their suggestion to explore such a device and useful conversations.

Conflicts of Interest: The authors declare no conflict of interest.

\section{Abbreviations}

The following abbreviations are used in this manuscript:

PET Polyester

CFD Computational Fluid Dynamics

HEPA High Efficiency Particulate Absorbing

FFU Fan Filter Unit

AG Aerosol Generator

HVAC Heating, Ventilation, and Air Conditioning

\section{Appendix A. Calibration Protocol}

A home-built calibration box (Figure A1) is used to calibrate the absolute particle number produced by the AG. The box has two $D=6$ inch $(15.24 \mathrm{~cm})$ diameter ports cut on opposing sides. One port as an air exhaust connected to an electric fan through a duct which pulls air from the box. The other port serves as an air intake, directly from the room. Mounted in the the entrance to the exhaust port, a sampling tube with one end connected to the particle counter samples the aerosol number concentration produced by the particle generator. The particle counter is factory calibrated with a $F_{c}=0.1 \mathrm{CFM}=0.17 \mathrm{~m}^{3} / \mathrm{h}$ input air flow rate. We measure the air face velocity $v_{b}$ at the box intake port using an anemometer and derive the total air flow $F_{b}$ generated by the electric fan $F_{b}=v_{b} \times\left(\pi D^{2} / 4\right)$. Assume aerosol particles are well mixed and diluted inside the calibration box, the sampling tube 
collects $F_{c} / F_{b}$ of the total particle generated. The calibration box essentially works as an aerosol number concentration attenuator with an attenuation factor $A t t=F_{b} / F_{c}$.

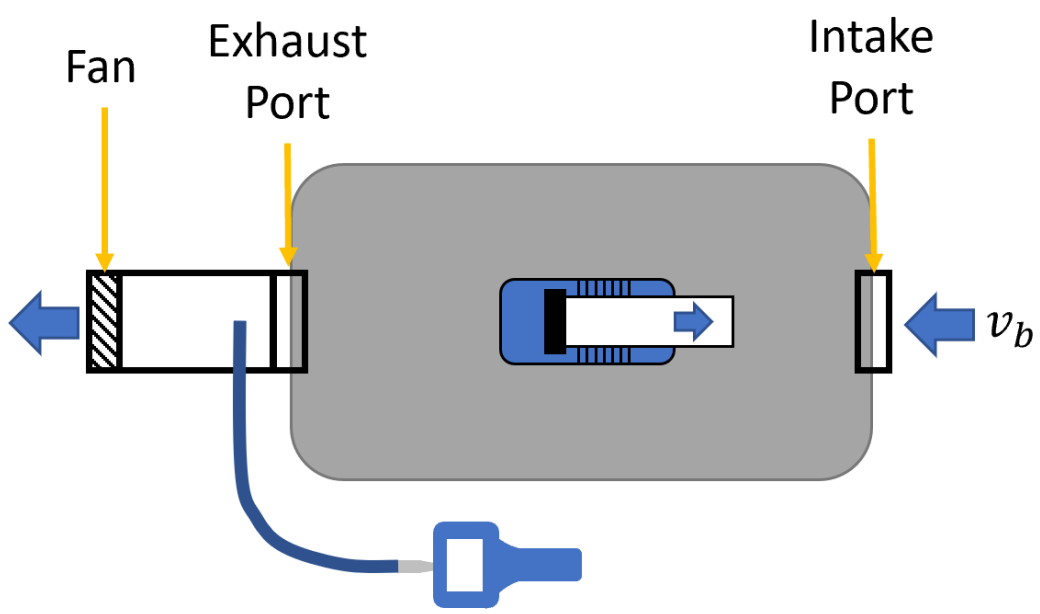

Figure A1. Schematic of the home-built calibration box.

Using our home-built calibration box under "operational conditions", we measured an intake port air velocity $v_{b o x}=1.75 \mathrm{~m} / \mathrm{s}$, indicating a net air flow rate around $F_{b}=67.5 \mathrm{CFM}=115 \mathrm{~m}^{3} / \mathrm{h}$ through the box. Attenuation of aerosol number concentration provided by the calibration box is then $A t t=F_{b} / F_{c}=675$. During the calibration process for the small space test, the particle counter records an aerosol number concentration around $\rho_{c}=2.25 \times 10^{5}$ particles/L, converted to particle count rate of $R_{c}=\rho_{c} \times F_{c}=1.06 \times 10^{4}$ particles $/ \mathrm{s}$. The particle generating rate of the generator can be then calculated as $R_{g}=A t t \times R_{c}=7.17 \times 10^{6}$ particles $/ \mathrm{s}$. In the small space with $F_{r}=300 \mathrm{CFM}=510 \mathrm{~m}^{3} / \mathrm{h}$ of fresh air exchange rate, the equilibrium aerosol number concentration is estimated to be $\rho_{r}=R_{g} / F_{r}=5.05 \times 10^{4}$ particles $/ \mathrm{L}$ with this calibration result, which is in good agreement with the direct measurement result $(4.82 \pm 0.04) \times 10^{4}$ particles $/ \mathrm{L}$.

\section{References}

1. Lu, J.; Gu, J.; Li, K.; Xu, C.; Su, W.; Lai, Z.; Zhou, D.; Yu, C.; Xu, B.; Yang, Z. COVID-19 Outbreak Associated with Air Conditioning in Restaurant, Guangzhou, China, 2020-Volume 26, Number 7-July 2020-Emerging Infectious Diseases journal-CDC. Emerg. Infect. Dis. 2020, 26, 1628. [CrossRef] [PubMed]

2. Liu, Y.; Ning, Z.; Chen, Y.; Guo, M.; Liu, Y.; Gali, N.K.; Sun, L.; Duan, Y.; Cai, J.; Westerdahl, D.; et al. Aerodynamic analysis of SARS-CoV-2 in two Wuhan hospitals. Nature 2020, 582, 557-560. [CrossRef] [PubMed]

3. Anderson, E.L.; Turnham, P.; Griffin, J.R.; Clarke, C.C. Consideration of the aerosol transmission for COVID-19 and public health. Risk Anal. 2020, 40, 902-907. [CrossRef] [PubMed]

4. Asadi, S.; Bouvier, N.; Wexler, A.S.; Ristenpart, W.D. The coronavirus pandemic and aerosols: Does COVID-19 transmit via expiratory particles? Aerosol Sci. Technol. 2020. [CrossRef] [PubMed]

5. Yu, I.T.; Li, Y.; Wong, T.W.; Tam, W.; Chan, A.T.; Lee, J.H.; Leung, D.Y.; Ho, T. Evidence of Airborne Transmission of the Severe Acute Respiratory Syndrome Virus. N. Engl. J. Med. 2004, 350, 1731-1739. [CrossRef]

6. Tang, S.; Mao, Y.; Jones, R.M.; Tan, Q.; Ji, J.S.; Li, N.; Shen, J.; Lv, Y.; Pan, L.; Ding, P.; et al. Aerosol transmission of SARS-CoV-2? Evidence, prevention and control. Environ. Int. 2020, 144, 106039. [CrossRef]

7. Wells, W.F. On air-borne infection. Study II. Droplets and droplet nuclei. Am. J. Hyg. 1934, 20, 611-618.

8. Stadnytskyi, V.; Bax, C.E.; Bax, A.; Anfinrud, P. The airborne lifetime of small speech droplets and their potential importance in SARS-CoV-2 transmission. Proc. Natl. Acad. Sci. USA 2020, 117, 11875-11877. [CrossRef] [PubMed]

9. Centers For Disease Control and Prevention. SARS-CoV-2 and Potential Airborne Transmission. 2020. Available online: https:/ / www.cdc.gov / coronavirus/2019-ncov/more/scientific-brief-sars-cov-2.html (accessed on 20 July 2021).

10. Alsved, M.; Matamis, A.; Bohlin, R.; Richter, M.; Bengtsson, P.E.; Fraenkel, C.J.; Medstrand, P.; Löndahl, J. Exhaled respiratory particles during singing and talking. Aerosol Sci. Technol. 2020, 54, 1245-1248. [CrossRef]

11. Xie, X.; Li, Y.; Sun, H.; Liu, L. Exhaled droplets due to talking and coughing. J. R. Soc. Interface 2009, 6, S703-S714. [CrossRef] [PubMed] 
12. Social Distancing. Available online: https://www.cdc.gov/coronavirus/2019-ncov/prevent-getting-sick/social-distancing.html (accessed on 20 July 2021).

13. Browning, M.H.; Larson, L.R.; Sharaievska, I.; Rigolon, A.; McAnirlin, O.; Mullenbach, L.; Cloutier, S.; Vu, T.M.; Thomsen, J.; Reigner, N.; et al. Psychological impacts from COVID-19 among university students: Risk factors across seven states in the United States. PLoS ONE 2021, 16, e0245327. [CrossRef] [PubMed]

14. Li, H.Y.; Cao, H.; Leung, D.Y.; Mak, Y.W. The psychological impacts of a COVID-19 outbreak on college students in China: A longitudinal study. Int. J. Environ. Res. Public Health 2020, 17, 3933. [CrossRef] [PubMed]

15. Gupta, J.K.; Lin, C.H.; Chen, Q. Characterizing exhaled airflow from breathing and talking. Indoor Air 2010, 20, 31-39. [CrossRef] [PubMed]

16. Ueki, H.; Furusawa, Y.; Iwatsuki-Horimoto, K.; Imai, M.; Kabata, H.; Nishimura, H.; Kawaoka, Y. Effectiveness of face masks in preventing airborne transmission of SARS-CoV-2. MSphere 2020, 5, e00637-20. [CrossRef] [PubMed]

17. Noti, J.D.; Lindsley, W.G.; Blachere, F.M.; Cao, G.; Kashon, M.L.; Thewlis, R.E.; McMillen, C.M.; King, W.P.; Szalajda, J.V.; Beezhold, D.H. Detection of infectious influenza virus in cough aerosols generated in a simulated patient examination room. Clin. Infect. Dis. 2012, 54, 1569-1577. [CrossRef] [PubMed]

18. Van der Sande, M.; Teunis, P.; Sabel, R. Professional and home-made face masks reduce exposure to respiratory infections among the general population. PLoS ONE 2008, 3, e2618. [CrossRef] [PubMed]

19. Lai, A.; Poon, C.; Cheung, A. Effectiveness of facemasks to reduce exposure hazards for airborne infections among general populations. J. R. Soc. Interface 2012, 9, 938-948. [CrossRef] [PubMed] 